\section{Summer School in Biology and Health}

THE Central Council for Health Education has been able to secure the services of eminent men of science and educationists for its Summer School in Biology and Health, to be held during August 4-14 at the Chelsea Polytechnic, London, under the joint direction of Mr. L. J. F. Brimble and Principal F. J. Harlow. Among the lecturers (subject to war emergency) will be Sir John Russell, Prof. C. W. Valentine, Prof. Winifred Cullis, Prof. J. R. Marrack and Prof. Lancelot Hogben. The mornings will be devoted to lectures by biologists and medical men; the afternoons to seminars, open forums and visits to museums, experimental stations, etc.; during the evenings lectures will be given on "Biology and Health", "Early Childhood", "Problems of Sex Education", "Social Aspects of Nutrition", "Biology as a Social Science", and "Agricultural Developments in the U.S.S.R.". Time will, of course, be left for recreation and social functions.

The first three days of the School should be of interest to all teachers, educational administrators, youth leaders, nursery school and play centre workers, school nurses, and indeed all who have to do with children. The final week will be planned specially for teachers of biology and those interested in that subject. The fee for the first three days only will be two guineas, and for the full ten days five guineas, in each case plus half a guinea registration fee. These figures include lunch, tea and dinner each day. The School has been approved by the Board of Education, and many education authorities will be prepared to consider applications for financial assistance to attend the course. Further details can be obtained from : Mr. Cyril Bibby, Education Officer, Central Council for Health Education, Tavistock House, Tavistock Square, London, W.C.I.

\section{Rat Infestation on Vessels}

Dr. Robert Olesen, medical director, and G. C. Sherrard, acting assistant surgeon of the United States Public Health Service, state that the records available at the New York Quarantine Station since 1924 show a considerable number of fumigations of ships though not an unduly high average of rats recovered from each vessel (Public Health Rep., 57, 1966; 1942). The influence of war on fumigation of vessels is shown by the fact that since 1940 the number of fumigations has gradually increased, and the average rat recoveries from each vessel have been greater than during previous years. In spite of the losses of trained staff, the Public Health Service maintains surveillance over vessels entering United States ports, though this is becoming increasingly difficult owing to rodent control being submerged by purely war effort.

\section{Silkworm Rearing}

WE have received a copy of a small publication in paper cover entitled the "Silkmoth Rearer's Handbook", which has been produced as volume 6 of the Amateur Entomologist (price 5s., postage 4d.; from Miss P. L. Rogers, 19 Crescent Road, London, N.8). This little work of seventy-two pages contains four plates of photographs of different silkmoth larvæ and more than twenty text-figures of the moths, their cocoons, etc. It includes instructions on the making of rearing and forcing devices, how to overcome the difficulties of pairing these giant moths and of obtaining fertile eggs, the problems of moulting, pupation and emergence, obtaining initial stocks, hybridization and many other matters of practical value. Sixty-seven species are described in detail, the notes including short descriptions of all stages of many of the species, together with specific pairing and rearing methods, food-plants acceptable in Britain and other information. The book is a reference guide which should prove of interest to all lepidopterists.

\section{The Badger in Britain}

THE Cumberland Nature Club of Cockermouth is organizing a nation-wide protest against the action of the Cumberland War Agricultural Executive Committee in including the badger in the list of 'vermin' recommended for destruction by the pests officer. The usefulness of the badger's habits has long been accepted in natural history circles, although in game preservation and rural circles it still suffers persecution for the misdeeds of the fox or occasional poultry raids by single individuals. The badger, with the fox and the stoat, is a natural 'brake' upon the rabbit population of the countryside. Its diet com. prises fruit, roots, small rodents, contents of wasps' ard bees' nests, rabbits, and sometimes small birds on the ground, and decaying animal or vegetable matter.

\section{Polish Institute of Arts and Sciences in America}

FURTHER evidence of the indomitable determination of Polish men of science and men of letters to defeat the Nazi plan to destroy the cultural and intellectual life of Poland is given by the publication of the first number of the quarterly Bulletin of the Polish Institute of Arts and Sciences in America. As is explained in the introduction, the aim of this bulletin is two-fold. It will serve as the journal of the Institute itself and to replace, for the duration of the War, the International Bulletin of the Polish Academy. It contains a history of the struggle for Polish culture up to the foundation of the Polish Institute of Arts and Sciences in America, in December 1941, and gives details of the activities and programmes of the sections of that Institute: historical and political sciences; history of literature and arts ; law and social and economic sciences; pure and applied sciences; and educational problems.

Papers and lectures delivered at the Institute (in some cases published both in Polish and English) include the inaugural address given by Prof. Bronislaw Malinowski, first president of the Board, who died suddenly on the following morning; a report by Prof. Oskar Halecki, director of the Institute: "Critical, Pre-Critical and Post-Critical States of Liquid Substances" by Wojciech Świetostawski ; and "The Aerodynamical Explanation of Cosmic Vortices" by Gustaw Mokrzycki. A list of books, articles, and reviews published by members of the Institute, not only in the Institute's own publications but all over the world, constitutes a valuable record of Polish contributions to science and letters. Tribute is paid to the many Polish professors, lecturers and other scholars who have died under German occupation or in concentration camps, a record which cannot fail to stir a desire to assist in every way the efforts of those men who are striving to carry on, in Great Britain through the Association of Polish University Professors and Lecturers and in the United States through the Polish Institute of Arts and Sciences, the intellectual activities so essential to the future of their country. 